\title{
Third-year medical students' choice of future careers
}

\author{
Rathi Mahendran ${ }^{1}$, Edimansyah Abidin'², Birit Broekman ${ }^{3}$, \\ Peh Lai Huat ${ }^{4}$, Kua Ee Heok ${ }^{5}$
}

\begin{abstract}
We determined future career choices of 222 third year medical students and found that $94.6 \%$ wanted to be clinicians. No one considered a full-time career in research or the clinician-researcher track. This highlights the need to facilitate medical students' decision-making on their career choice which would have a significant impact on the development of healthcare and its services.
\end{abstract}

\section{Introduction}

Traditional career tracks for physicians to pursue their vocation in medicine were clinical practice, research and academia (Borges et al, 2010). Today's growth and diversification of healthcare to business and industry has expanded non-traditional fields and widened career choices. In 2000, the Association of American Medical Colleges (AAMC) Annual Medical School Graduation Questionnaire (GQ) data showed "a growing number" intending to enter non-traditional fields (Richard et al, 2001). While there is much research on specialty choices and interests, we noted a dearth in the literature on the issue of career tracks.

\footnotetext{
${ }^{1}$ Senior Consultant Psychiatrist, Department of Psychological Medicine, National University Hospital, Department of Psychological Medicine, Yong Loo Lin School of Medicine, National University of Singapore

${ }^{2}$ Research Fellow, Research Department, Institute of Mental Health/Woodbridge Hospital

${ }^{3}$ Consultant Psychiatrist, National University Health System

${ }^{4}$ Senior Consultant Psychiatrist, Changi General Hospital

${ }^{5}$ Senior Consultant Psychiatrist, National University of Singapore

Corresponding author:

Dr Rathi Mahendran

Senior Consultant Psychiatrist, National University Hospital, NUHS Tower Block, level 9, 1E Kent Ridge Road Singapore 119228

E-Mail: medrm@nus.edu.sg
}

\section{Methods}

As part of a study on attitudes towards psychiatry and mental illness, third year medical students at the Yong Loo Lin School of Medicine, National University of Singapore, were asked about intended career choices upon graduation. The study had approval from the Ethics Board National Healthcare Group. Data was analyzed using SPSS version 16.

\section{Results}

Of the 382 medical students who participated in the survey, (March 2008 to April 2009, participation rate $79.3 \%) 222$ responded to the question on their future career field. There were 125 males $(56.3 \%)$. The ethnic distribution was as follows: Chinese $90.1 \%$, Indians $6.8 \%$, Malays $1.4 \%$ and 'others' $1.8 \%$. The majority were in the 21 to 25 years of age group (217, 97.8\%).

On the question of career tracks they were considering, an overwhelming number (210, $94.6 \%)$ wanted to be clinicians with $3(1.4 \%)$ considering a clinician-administration track and $1(0.5 \%)$ considering a clinician-academic track. Five students $(2.3 \%)$ were considering a purely administration track (in healthcare) and $3(1.4 \%)$ wanted a full-time academic track. Not a single student was considering a clinician-researcher track or a full-time career in research.

There was a significant gender bias, with males $(p=0.03)$ more likely to choose to be a clinician or the clinician-administrator or clinician-academic track.

In relation to specialty choices, there were slightly more students without a preferred specialty $(114,51.4 \%)$ and there was no 
significant gender difference. Also there were no significant differences in age, race or specialty choice in relation to future career choices.

\section{Discussion}

Research has shown that multiple factors influence medical students decisions on a career track. In academic medicine, fairly specific factors such as early involvement and exposure to research in medical school and residency have been identified (Straus et al, 2006). Similarly, role models and mentors impact the decision to pursue academic medicine (O'Sullivan et al, 2009). While academia may provide intellectual challenges and stimulation, literature reviews show that this aspect quickly fades as the residency progresses (Borges et al, 2010). Fox found that although the magnitude of the effect was not large, 'indebtedness' could reduce the likelihood of a full-time career in academic medicine (Fox, 2002).

There has also been much research on personal factors such as prestige, anticipated lifestyle and financial expectation. Additionally, medical students perceptions of their own strengths and weaknesses and their clinical experiences during rotations would impact future career choices. (Richard et al 2001).

In Singapore, the concept of academic medical centers is evolving. Students are trained in academic medical hospitals and regional general hospitals. In the former, physicians have distinct educational roles. In the latter, clinicians are 'expected to teach' without necessarily a direct emphasis on the education role. Again the time committed to teaching by clinicians is different in various hospitals and their roles and responsibilities may not be clear to students. This may have shaped the perception and did not provide the opportunity for them to consider a clinicianacademic track.

A clinician researcher track is available locally for doctors who wish to work primarily as clinician-scientists or researchers. However the pressure to publish and obtain research grants is a disincentive. Associated with this is the lower income variable compared to the clinical specialty tracks. Medical students in Singapore complete a research project during a sixteen week elective period in their fourth year and also undertake a supervised group research project as part of community health training. As third year students they would not have done any of this and lacked sufficient exposure or experience in research to shape their views.

There are limitations to our findings. The literature review revealed that terminology differs. Some centers talk of clinical-educators and, clinician-teachers. Job descriptions and time commitment to teaching and research is very much dependent on each hospitals' needs and negotiating of employment. Salaries would be determined by varying human resource practices and may come from revenue generated by clinical services. These vast differences make comparisons difficult and would not be entirely clear to respondents in the study.

As third year medical students in the midst of first year in clinical rotations through different specialties, the academic and non-academic experiences are still ongoing and exposure to mentors sometimes yet to come. Furthermore, this was a cohort study and we did not followup with students to understand subsequent changes in career choices. Nonetheless, there is a cause for concern especially as we note some choices such as research do not register at all.

\section{References}

Borges, N.J., Navarro, A.M. \& Grover, A. et al. (2010) How, when and why do physicians choose careers in academic medicine?, $A$ literature review, Academic Medicine, 85(4), pp. 680-686.

Fox, M. (2002) Medical Student Indebtedness and the propensity to enter academic medicine, Health Economics, 12(2), pp. 101-112. [Online],

O'Sullivan, P.S., Niehaus, B. \& Lockspeiser, T.M. et al. (2009) Becoming an academic doctor: perceptions of scholarly careers, Medical Education, 43(4), pp. 335-341.

Richard, G.V., Nakamoto, D.M. \& Lockwood, J.H. (2001) Medical Career Choices: Traditional and New Possibilities, Journal of the American Medical Association, 285, pp. 2249-2250.

Straus, S.E., Straus, C. \& Tzanetos, K. (2006) Career choice in academic medicine: systematic review, Journal of General Internal Medicine, 21(12), pp. 1222-1229. 